The narrative psychology of community workers

Michael Murray

And

Friederike Ziegler

Published in Journal of Health Psychology 


\title{
The narrative psychology of community workers
}

\begin{abstract}
Community health psychology is an approach which promotes community mobilisation as a means of enhancing community capacity and wellbeing and challenging health inequalities. Much of the research on this approach has been at the more strategic and policy level with less reference to the everyday experiences of community workers who are actively involved in promoting various forms of community change. This paper considers the narrative accounts of a sample of 12 community workers who were interviewed about their lives. Their accounts were analysed in terms of narrative content. This revealed the tensions in their everyday practice as they attempted to overcome community divisions and management demands for evidence. Common to all accounts was a commitment to social justice. These findings are discussed with reference to opportunities and challenges in the practice of community work.
\end{abstract}

Keywords: Narrative, Identity, Community 


\section{The narrative psychology of community health workers}

The recent publication of the edited collection by Campbell and Cornish (2014a) has re-invigorated discussion about community health psychology. Over the past ten and more years there has been debate about the potential value of community health psychology as an alternative to the individual victim-blaming approach which has been dominant within mainstream health psychology. However, the initial enthusiasm as reflected in the earlier collection by Murray and Campbell (2004) has been dampened by a caution that community development/mobilisation approaches have been co-opted by dominant interest groups. Rather than empowering local communities and challenging health inequalities it has been argued that such approaches have opened up new ways of exploiting vulnerable groups.

Campbell \& Cornish (2014b) have called for community health psychology to be 'extended and rejuvenated to take account of the rapid and often dramatic changes in social relations over the past 50 years' (p. 3). In particular, they considered issues of power and identity and multiple forms of community mobilisation. Campbell (2014) has reviewed the various debates and apparent contradictions in community approaches and argued against the one-size fits all (the onesie) approach. Rather she argued for a more sophisticated approach in which small and larger challenges to dominant interest groups all play a role in the broader move to promote health equity. This article is a small contribution to this debate. Rather than focusing on grand schemes of the theorist or of the views of disadvantaged communities, this article focuses on the perspective of the community worker. It is interesting that in much of the discussion their views have largely been ignored. In many ways they are often portrayed as ciphers of larger schemes with little sense of agency. A narrative approach opens up an opportunity to grasp their perspective and how they deal with contradictions in their everyday practice.

Although community approaches to health improvement have largely focused on work in developing countries, in industrialised nations there has been increasing political interest in the concept of community and the potential of community initiatives to overcome a range of social, economic and health challenges on a local level. In Britain the New Labour government introduced its New Deal for Communities (NDC) initiative in 1997. The aim of this initiative was to actively involve local communities in the regeneration of their often severely disadvantaged neighbourhoods. Rather than being the traditional passive consumers of services, residents were now being encouraged to play a more active role in the organization of their communities. The election of the Coalition government in 2008 did little to change this policy thrust but rather intensified it. These developments in policy have not gone unchallenged by observers. Hancock, Mooney and Neal 
(2012) have detailed some of the contradictions and potential conflicts in the policy in particular the neglect of social inequalities and the potential dangers of further victimising already disadvantaged communities.

A central feature of these community initiatives has been the appointment of a range of community workers, e.g., community health workers, regeneration officers and ward coordinators. Their role has been to promote greater involvement of the residents of working class neighbourhoods in decisions about the development and management of local housing, health and social services, and greater involvement in various health-related activities. These community workers are located at the front-line of government initiatives to implement policies to promote greater community involvement.

There have been a number of surveys of the characteristics of such community workers in the UK (e.g. Glen, Henderson, Humm, Meszaros \& Gaffney, 2004; Sender, Carlisle, Hatamian \& Bowles, 2010). The report by Sender et al (2010) found that the workers came from a variety of social and educational backgrounds and worked in different settings. What united them was a general orientation to community development as a "long-term, value-based process which aims to address imbalances in power and bring about change founded on social justice, equality and inclusion". In developing standards for training these workers, Life Long Learning (2009) identified five key values as lying at the heart of any community development activity. These were: equality and antidiscrimination, social justice, collective action, community empowerment, and working and learning together.

The argument that personal values play a central role in shaping our everyday practices and sense of identity has been developed by Hitlin (2003). He used Schwartz's (1994) definition of values as "desirable trans-situational goals, varying in importance, that serve as guiding principles in the life of a person or other social entity". These values "develop in social contexts, draw on culturally significant symbolic material, and are experienced as a necessary and fundamental, but noncoerced, aspect of self" (Hitlin, 2003: 121). In a study of student volunteers Hitlin examined the relationship between volunteer identity and values. He found that the two 'self-transcendent' values of universalism and benevolence were found to be typical of the volunteer identity. There was a stronger relationship with the value of benevolence (true friendship, honesty, forgiveness, helpfulness) than with the value of universalism (equality, a world at peace, social justice, broadmindedness). Hitlin suggested that this may reflect a greater commitment to interpersonal relationships than to more social/community issues among the student population. This finding agrees with a study by Omoto, Snyder and Martino (2000) who found that younger hospice 
volunteers were more motivated by interpersonal concerns whereas older volunteers were more motivated by service and community concerns. Hitlin also found in his study that the selfenhancement values (power and achievement) were negatively associated with volunteer identity.

Fagermoen (1997) explored the role of values in the occupational identity of nurses. The surveydata revealed that the nurses held both moral and work values. While concerns for human dignity and altruism were identified as the most prominent moral values, intellectual and personal stimulation were the most important work values. Narrative analysis of the interview-data identified altruism as the overall philosophy underlying patient care while concern for human dignity appeared as a core value.

While values may be an important underpinning of community work there is less evidence of how these connect with everyday experiences. The various reports have largely been descriptive accounts of the background and training of community workers and less about their everyday practice. Purcell (2011) in his study of trainee community workers noted how they became aware of the restrictions on their work by their employers but did not know a way out of this conundrum. He suggested a return to a broader Freirean strategy of critical engagement whereby both the community worker and the community both learn from each other, the restrictions on their actions and how they can develop broader strategies of change. In this way, he argues, community work can take "its lead from the needs and desires of local people, rather than from agency-dominated agendas" (p. 15). Similarly, Wiggins et al (2013) argue that Freire's popular education provides a foundation for training community health workers. However, there is a need to learn more from the actual experiences of community workers.

In this paper we seek to explore the everyday character of community work. We use narrative as our theoretical framework as it enables us to explore the interaction between the person and the situation (Murray, 2014). While the primary focus is on the variability in the personal narratives of the community workers, we are also interested in how these connect with the wider societal narratives. Hammack (2007) argues that it is though the process of engagement with these larger societal narratives that we define our identities. Thus in exploring their narrative accounts of their everyday life will enable us to explore how the community workers engage with broader discourses. In addition, this connection with the societal narratives will also allow us to explore the relationship between big and small stories which have recently been the subject of discussion (Bamberg, 2008; 
Freeman, 2009). Sools (2012) has used this distinction to consider the nature of narrative within the counselling encounter.

\section{Method}

The narrative accounts were collected as part of the Call-Me project which was a participatory action research project designed to evaluate the development and impact of community based initiatives intended to promote enhanced social activity among older residents of disadvantaged urban neighbourhoods. The project took place in four different areas of a northern UK city during 20092011 (see Murray \& Crummett, 2010). As part of the project a number of professionals and local stakeholders working with older people in the city and neighbourhoods were invited to two workshop meetings. At the first meeting researchers and stakeholders agreed that interviews would be carried out in order to give professionals an opportunity to expand on their views on challenges and opportunities in working with older people. We interviewed a total 12 individuals who were involved in various forms of community activity throughout the city. These participants included regeneration officers, housing association officers, ward officers and community health workers. All of the participants were in the age range mid 40 to mid 50.

The interviews adopted a biographical format. They were designed to provide an opportunity for the participants to reflect on their lives and careers, but largely concentrated on their community work. Thus the interviewer began by encouraging the participants to reflect upon their social and personal backgrounds and then to consider their entry into and experiences of community work. Each of the interviews lasted approximately 90 minutes although some were longer and a few shorter. In one case the interview took place in two sessions in view of its length (3 hours). All of the interviews were audio-taped and took place in the workplace of the stakeholders. All interviewees consented to participation and the use of anonymised interview transcripts for research. All names in this report have been changed by the authors and identifying features removed.

Each of the interviews was transcribed and read through several times making extensive notes on the form and content of the account (Murray, 2014). This enabled us to grasp what they were doing as community workers but also why they were doing it. It also enabled us to grasp how the community worker was positioned in relation to both the community and their employers. We were interested in how participants structured their narratives and what they identified as the key issues in community work. In particular, we were interested in evidence of the role of values in providing a sense of coherence in their narrative accounts and how the personal narratives/stories 
of these community workers engaged with broader societal narratives about empowering disadvantaged communities.

We should note our own values which include a commitment to social justice and working through both research and practice to create a better world especially for those who are most disadvantaged. It was this that encouraged us both to research this topic but also to better understand the processes of social change and how they can be better promoted (see Dutt \& Grabe, 2014).

\section{Findings}

The community workers' narratives were generally ones of ongoing struggle to enhance the capacity of community residents. The struggle was with the sense of fatalism and exclusion reported by many of the residents but it was also with various agencies and the many social factors which were perceived as contributing to that exclusion. Although the content of the narratives differed depending upon their type of work, a commitment to the values of social justice and community empowerment provided a sense of coherence to them. The values of personal achievement were less apparent but rather a commitment to community enhancement was central. In addition, personal achievement through moving away from the front-line of community work into management was frowned upon.

\section{Who are they?}

The CWs came from different social backgrounds but most had entered into community work because it gave them an opportunity of creating a better world. Most of the CWs had received minimal training and basically learnt on the job. This meant that they rarely referred to broad theoretical concepts but occasionally to certain concepts which they had come across in policy documents or in workshops. To illustrate the different approaches taken by community workers we consider three cases. These were selected as they illustrate both the commonalities and variability in the practice of CWs. Alison was a community health worker employed by an agency determined to promote local forms of health action and reduce health inequality. Jane was a council employee whose work revolved around improving access to services. Paul was a council regeneration officer who worked to ensure that council tenants were actively consulted about regeneration plans.

While the nature of their work varied there was a common commitment to social justice. However, the form in which this value was expressed depended upon the actual confines of the work. Alison had taken a drop in salary because she felt that community work accorded more with her values. She provided a very developed view of her social justice values and how this was connecting with 
her current job although she was somewhat unsure about the real impact of her work on people's lives:

I used to be very, very proud of this job, really proud to be part of this, and I do, it meets my belief that we should challenge health inequalities; we should change inequality in general. It meets my beliefs so much, 'cos you know, l'd love to imagine that there was some impact, and I'd like to be meeting people, I'd really like to be meeting people who have got, erm, challenging lives and offer, you know, a little tiny bit of change. And I also love, erm, the fact that we can work in a slightly, well in a very, we have been able to work in a very creative way.

Jane detailed her frustration at the lack of respect shown by the council towards people from disadvantaged backgrounds. She saw her role as ensuring that such people had appropriate services. Although Jane referred to social justice this was connected to the right to accessing better services rather than with arguments for broader structural change. Social justice for her was treating people with respect as part of delivery of a service, no matter what their social background. It was what underpinned her work in different capacities as a council employee.

“You shouldn't treat anybody any different 'cos they're on benefit [...]My dad was a strong socialist, brought up socialist, has real strong kind of socialist attitudes, but now I'm at this age thinking about the concerns that my parents have gone through, thinking about my own family situation. I sometimes do find myself getting angry with the claim benefit culture but from a kind of perspective of the system's wrong, you know. Not that people are wrong for making claims."

The value underlying Paul's work was to ensure that those council tenants who had traditionally been ignored and marginalised now had the opportunity of participating in decisions about their neighbourhood. For him social justice was tied up with equal opportunity.

Many of the CWs referred to their family or personal background as the origin of this commitment to social justice. For example, Jane's father had strong socialist views and she had learnt the importance of social justice as a child:

Interviewer: "So do you think that this sort of engagement that you feel emotionally and personally with the communities comes from a sense of injustice? "

Alison: "Yes. Yes, that's what fires me. Absolutely. Going right back to those early days of being ... all the root back is injustice, all the time. Right back to the time when being ... 
injustice to me $[\ldots]$, seeing people badly treated when they came into a [...] office to make a complaint or just the total lack of respect that the council appeared to show people who were at the lowest point of their life."

Alison had experienced various personal disadvantages and felt that both she and the community with which she strongly identified were deserving of more.

\section{The small stories of everyday practice}

Much of the everyday practice of CW was informal conversation with community residents which could be compared with the sharing of small stories discussed by Sools (2013). Central to Alison's work was being present at all times. It meant working with the local residents, sharing their stories and providing support, i.e. being available when people most needed it. It was through this sharing of small stories that she could connect residents with the larger story of community change. As she said:

Our job is to be very consistent, always be ready and keep providing information, because one time you provide information and help if you're just there, you're available which is another part of the job, being available I think, erm, perhaps somebody will get on that cycle of change, you know, if it's as simple as that, if they get that motivator or, erm. But you've got to be around, you know, you can't withdraw that that's really hard for services, 'cos obviously if you don't get results in a six week period, you know, 'it's not working. I've got finite resources. I've got to deal with other things!'

A point that she came back to several times was the need to be open to the people she was working with; to share with them and to treat them as individuals each with particular strengths and problems:

This is a good one and I only learned this myself but this wouldn't be in any community development training manual anywhere, but one thing I would say, give a bit of yourself. And that was only something that I, that I learned ... and it kind of came natural. And I didn't do it because I thought it would be a benefit. I did it because I thought - or that it would help me -1 just did it because it felt kind of natural.

She went on to talk about how she got to know about individual family members. Admittedly, this information was confidential and she would not share it with authority. Further, to develop such a relationship with community residents required sharing details about her own life thus expressing her own value of equality: 
And that just made sense to me. But there'd be no professional that advises anyone who works in community development work, you know, to give a little of yourself. There might be, I don't know, I've not been on the course, have I? But I wouldn't imagine, you know. They'll talk to you all about, you know, how to develop groups and how you do this, that and the other and how you might confidence build a group, but [...] they feel more comfortable with you, they feel more open to talk about things, they get a better service from you because you know what the issues are, you know what they've got on.

This sharing of small stories enabled the CWs to connect with the community and vice versa. A key factor was identifying with the community - at least to an extent - or as Paul said, getting the area under your skin:

I think it is very difficult to get a proper sense of an area without sort of getting out and about and meeting people properly, and I think getting the area under your skin a little bit. Because otherwise, I think, unless you sort of feel a little bit like you're part of the community, you're never going to truly understand what people in that area want. And I mean there are extremes of it, don't get me wrong. I mean I've been in my previous job, I was practically living in [...] at times, 'cos I was spending so much of my time there, which is, I think you know, I, I really enjoyed it and I didn't have any problem with it. But it's not something I would ever go to the extreme of again, because l've got, you know, things outside of my work that I want to enjoy as well.

He still realised that he was not a member of the community but he wanted to get under the community's skin to gain this understanding. In response to a question about the best advice for a trainee community worker he replied:

Get out into the area as quick as possible. Get to know them, I think. Before you end up starting to make decisions on an area I would try and get as well versed in that area as you can, and the best way of doing that is to spend time out and about, walking around, getting to know people, trying to work out the balance of local politics, not in a political sense but, you know, in terms of what, you know, where people's allegiances lie in terms of certain individuals who, who, you know, who has clout, who doesn't, erm, and just, just get to know the area. And I think just try, I think, allow yourself to get an area under your skin a little bit [...] if you can position yourself in a way that you feel almost part of that community, and you feel that things that are happening are winding you up in the same way that they wind 
up local residents up, then I think you've got to a position where you are quite well, sort of, that you've got your finger on the pulse and, erm, but it's got to be tempered

Although he worked hard to involve the residents there was less evidence of the passion and emotional involvement of the social activist. As a manager he had to make a conscious effort to stay involved with the residents and events happening in the community.

\section{Envisioning new stories}

A central part of their work was convincing residents of a new community change narrative. Jane described how it was through the exchange of small stories that she was able to convince people of the potential of this community change narrative. Her role was to convince the residents that despite past experience it was possible to exert change and transform their living conditions:

So selling people this idea of this holistic change, making people believe that something, and at the time I'm still getting to grips with it myself, how are we going to make ... 'cos I had known that area for a long, long time and I'd grown up not far away from that area, so I kind of believed ... having to make myself believe it and regularly having conversations with people: 'Do you [...] honestly believe it's going to work?' [...] And you go 'Do you know what, I really think it is.' That was enough for some people to go 'Do you know what, I'm going to try and get a resident group set up around here. I'm going to try and get people mobilised.'

As a council employee she was torn between management and community demands. This led her to temper her enthusiasm for community change. She was not simply a spokesperson for the community but a council employee. She felt that as a council employee she had to be detached, as a CW she needed to be emotionally involved:

“You can't be too emotionally detached because unless you ... the emotional side of things comes from that ... the empathy, the sympathy situation. So in order to ... and you need to be able to support a group within the community. You need to have some sort of understanding and once you start to understand you can't, you can't stop your emotional feelings coming into a situation, you know. Whatever those issues might be that need to turn around. So I don't think I'Il ever lose that emotional attachment. I think that will always be there and I think that you couldn't do this job well, I don't think, if you didn't have that. But it's how those emotions are managed I think, that's the difference. But you'd recognise perhaps where you were becoming personally angry or agitated or frustrated and then think, hang on, no, I need to manage this better, and that's how we then, I think, you deliver better. So, yes, that was a positive learning experience." 
A particular frustration was the realisation that certain community programmes created false illusions in the potential for change. In these cases she felt that she was being used by management to convince the community residents that they could exert change in redevelopment plans when the council had no plans to allow for change:

"It was show the picture, you know, sell the dream to people! Don't allow them to question the what ifs."

It was this need to be honest that was essential in building relationships with the community residents. If the trust that was built was built upon a fiction then this could have very negative consequences for the community worker.

Alison felt that her job was to raise people's ambitions even more than was expected of her:

And it really does make a difference, because people's ambitions and their horizons are damn low! And I don't believe we as a service are doing anything to change that, in fact I think, I must say, my biggest criticism is that I think that we are really boxing people into a corner and saying, 'You can be.....the best you're going to be is working at a supermarket check-out, and you'll be damn glad of that job an all!', and I really think that's dangerous! That's dangerous to make us into a two tier, a really bad two tier society! I mean we are that anyway, a little bit, but talk about perpetuating equalities! So that's why it's difficult. That's why it's hard to get enjoyment because the things that l'd like to be able to do to help people have a different horizon, err, you know, what would be so bad if somebody from round here decided they were going to be a poet and make their fortune out of being a poet?

\section{The tensions with community}

Working in different neighbourhoods made the CWs aware of the many divisions within any community. These divisions were based upon a range of historical and contemporary factors and could seriously hinder attempt to promote whole community mobilisation. Alison was aware of the divisions within communities:

Even if it's the same culture there's still divisions within working classes, you know. There's the lower working classes ... I mean I don't know what divisions there are but there are certainly people who consider themselves, err, better than those who live on the council estate, that's one and then those are the ones that have managed like many community workers there was limited prior training - rather she developed skills through trial and error. 
This was coupled with the history of disadvantage and exclusion experienced by community residents as well as the frustrations she felt from management. Alison had become somewhat disillusioned with the reality of extent of change she could achieve through her work. Although her values remained the same she was questioning the ability of community work to reduce social inequalities. In these circumstances she had adjusted her ambitions and was content with achieving even small changes.

Paul was aware of the many different sub-groups within communities which could jeopardise plans for change:

It was just making sure that, even though they were from the community themselves, that they still adhered to, you know, sort of method of consultation that was going to make sure that as many people as possible, you know, were involved, 'cos obviously within any community you're going to have divides, whether it's in the middle of an area or whether you've got one side that's seen as the more aspirational place to live and the other is the bottom of the rung really. And I think when you get people in an area like that, no matter how hard you try, there is always that trade-off of 'Well she's only there for that ... el, he's only there for this, he's there to feather his own cap. And we were there really to avoid that happening and saying 'Well even if you've got opinions about that person, or even if you disagree with that person's politics, they still have a right to be involved in this process as a member of the community'.

\section{Working for change}

Jane was employed by the city council. She had left school early and started work with the council in a range of clerical posts. She had no formal qualifications but had learned about community development through trial and error. As a council employee Jane worked not only with community residents but also with a range of voluntary and statutory agencies. As she said:

'working with people who wanted to make things better for others, so volunteers, but doing a specific piece of work within the community, to people who wanted to campaign for change, people who felt that they deserved better from people who were providing a service to them. And just sounded like, this was proper customer care ...'

Throughout her account she stressed the importance of providing a 'good service' for those who used the council services. Her role had changed from one that was focused on providing services for individuals to one which aimed to work with whole communities such that they could get appropriate services and living conditions. 
In her everyday work Jane spent much of her time talking with community residents. Jane saw this as essential. It was through building relationships that she could begin to involve the residents more actively in various activities:

At the beginning we started building relationships, that was my job initially, start building relationships - lot of work going out, meeting people, selling the idea that we're going to get [...] of selling the idea that we were going to turn an area around, you know. That this wasn't just playing about, tarting up the edges and removing graffiti and putting the odd extra street light in, this was about big holistic change."

She was not building relationships for the sake of it; it was so that she could 'sell the ideal'.

\section{Lifestyle vs community change}

Many of the CWs were frustrated at the approach which focused on individual lifestyle change which they felt ignored the social conditions within which the residents lived. As Alison said:

Yeah, what can we do? And, but these are also like a red herring in a way because if $\mathrm{I}$, the minute I go out into the community and talk to people about their issues or needs in terms of health, very rarely, unless I really push it is it about diet and exercise ... it's a difficult one and it's not a simple lifestyle choice ... naivety is probably a kind word for it! It's very frustrating because that's not the reality at all, and it's not, particularly if you're working in a very poor community with all sorts of pressures on you.

In this setting of hardship and local community divisions Alison told a story of trying to work with the residents to promote local change. She accepted the insecurity and reduced financial reward that came with the new job because it aligned well with her own values. She felt that her job was hard to define because there were so many aspects to it.

Paul's narrative was one of the manager - he was the social side of urban regeneration. He wanted not just a change in the buildings but a change in the residents and how they were viewed by others:

Sort of changing, I think, views of an area and, more importantly than anything, changing the views of people that were living there at the time that, you know, aspiration wasn't just a thing that could just, sort of, be dreamt up and then forgotten about. It was, you know, it was a real delivery of something.

However, he realised that it was not he who could deliver this change the community had to be actively involved and that was his role: 
It comes back to that element, sort of old school of thought within regeneration, not to do to people but to do with people.

\section{The evidence straightjacket}

A common complaint among all of the CWs was the demands by their employer that they produce evidence of the impact of their work. They felt that unlike classical clinical interventions which measure change on a limited number of indicators it was not so simple with community work. Their everyday work with residents made them aware of the complexity of people's lives. They were frustrated by what they felt were the less sophisticated views of managers. Alison felt that management targets were artificial and did not connect with the everyday experience of community residents:

I mean there was a question in the interview I remember something about, you know, 'How are you going to balance up the needs of meeting the targets with the needs of the community?', you know, and I can't even remember what I said. But that was quite an interesting question, 'cos that was, that's always been the massive challenge. Because often the targets that drive us behind getting people to take up more exercise or become less overweight, it's so far away from what we are actually trying to do.

However, even at the more management level there was awareness of the problem of measuring impact. As a council/regeneration employee Paul had to produce evidence. He reflected on the problem of measuring empowerment:

If you want to start measuring the value of feeling empowered to local people, if you want to measure it on anything else then it's, I'm sorry but there isn't anything. I can't tell how many people feel empowered in the area because I don't have a magic wand that can miracle up those ' $x$ '. I can tell you how many tenants; associations there are in an area. I can tell you how many of them are active. I can tell you how many members most of them have got. I can't tell you for one second beyond those people that are on the list, how many of the wider community within the area that they claim to represent actually feel empowered, actually see that group as representing them. I think what, what is, is sort of spoken about right through the regeneration sector and the whole thing about community involvement and empowerment is, it's about real life experience and the voluntary work that people do and how much that gives then a social skill and builds confidence up. 
For Paul, community development was an intrinsic part of a just society. However, the quest for evidence meant that he searched for a range of indicators which he thought would impress his employers:

It just comes back to the whole thing about capacity around, you know, resident involvement and, you know, how do you measure timing against it? It hasn't got tangible outputs [...] Which is the difficulty and I think, I think when it comes to sort of justifying the role, I think we're, when we put the outputs together, I, the one that I always come back to and I always feel very, very comfortable about, sort of arguing the toss over in any conversation I have with somebody or in a job interview or anything else, if it came to like a job that are on the list, how many of the wider community evaluation, is I would say, 'How much money have I been able to influence coming into that area?, and if that's what you want then that's a tangible output.

\section{Discussion}

These findings have demonstrated the value of adopting a narrative approach to understanding the everyday experience of community work. The narrative perspective revealed the importance of family background and other experiences in promoting the value of social justice. The role of narrative was also apparent in the small stories which the CWs shared with community residents which enabled them to bond with the residents and engage them with the larger story of community change.

Our analysis of the narrative accounts of the community workers revealed the tensions in their everyday practice as they tried to engage residents in various forms of community change. A central theme was their commitment to helping to create a better world. It was this commitment to social justice that drove them to work often unsocial hours, to overcome many personal setbacks and to persist when the evidence of impact was limited. Even small change was held up as being beneficial when the community residents experienced so many disadvantages. While some CWs felt that it was sufficient to engage the community in discussion about services others felt that a focus on small instrumental changes was underestimating the broader change potential. They felt that many community talents were not being developed.

The role of the $\mathrm{CW}$ at the interface between the community and their employer contributed to ongoing tensions around the extent of change. Empowering the communities could bring them into conflict with their own employers who in turn could place obstacles in the path of change. They 
could go so far but no further. The failure to deliver on promises could bring them into conflict with community residents. This in between role meant that they were subject to pressure from both sides. Their job was balancing these competing interests - raising community aspirations but at the same time recognizing the obstacles to change.

Much of the everyday work of the community workers involved sharing stories with the residents. They knew their sorrows and their joys, their successes and their frustrations and at the same time they worked towards promoting a new story of change. Here we can see the connection between the small and big stories (see Bamberg, 2011; Freeman, 2011; Sools, 2013). The sharing of everyday small stories was essential to their work. It was not ephemeral but rather a key means of getting to know the community and building a relationship with the residents. It was through this sharing of small stories that the community workers came to identify themselves more with the community although they were still not part of the community. It was through positioning themselves in this context that the community workers were able to gain the residents' trust and to introduce a bigger story of change.

These bigger stories of change offered possible new ways of living. The role of the community worker is to convince people of the potential of such a new story. In a similar vein Tilly (2002) has argued that stories "do essential work in social life, cementing people's commitments to common projects, helping people make sense of what is going on, channelling collective decisions and judgements, spurring people to action they would otherwise be reluctant to pursue" (p. 27).

Jarvis et al (2011) in their study of regeneration in an inner-city area noted how trust was a key element in the process. They found substantial levels of mistrust both towards council officials and towards their neighbours. Without trust it was difficult to generate community action. In sharing small stories the community worker began to build that trust but it was tested in their ability to promote positive change with the community. If they were seen to be promoting the interest s of the outsider then that trust could be challenged and their ability to involve the residents in the larger story of change was compromised.

At the centre of the narrative accounts of the community workers was a commitment to social justice, in creating a better world for those who had been excluded from many opportunities, to enable community residents to consider a new story of potential. This social justice focus provided coherence to their narrative accounts. The community worker is drawing upon a broader social 
discourse about social justice. The narrative that is presented is of the dedicated community worker struggling against many difficulties to help make a better world. When her / his attempts to enhance community quality are obstructed $\mathrm{s} /$ he is frustrated and angry. However, this broad social value was overlaid with other broader discourses - social activism, consumer advocacy and efficiency/managerialism (Rayner, Scarborough \& Allender, 2006) which they drew upon depending upon their actual working role.

In their different ways the community workers were presenting McAdam's (2013) redemptive narrative which he argues characterises 'the good people'. In developing this narrative identity McAdam draws upon Erikson's (1963) concept of generativity which he thought of as a challenge facing people in mid-life. It was characterised by a need to make the world a better place. At midlife some people will have the opportunity to reflect on their lives and perhaps their broader contribution to humanity. The community worker's narratives were filled with everyday details of their work to enhance the capacity of those who were excluded or neglected.

This approach to the study of community development explored the central role of the community worker who despite being convinced of the value of social justice found that in practice it was not always easy to achieve. The passion to achieve positive change in the lives of the community residents was driven by a frustration at the inequities of the broader society and how it impacted on the lives of the community residents with whom they felt much in common.

In previous work (e.g. Murray, 2012a, b) I have emphasised the scholar-activist as the model for a reinvigorated health psychology. However, this model often starts with the scholar rather than the other way around. There is an obvious need for a more active exchange between those who work primarily in the academy and those who are based in the community. Narrative psychology can provide a framework for understanding both the development of trusting relationships with community residents but for orienting them towards change. The challenge is now to work with CWs in refining this framework. For example, in her review Campbell (2014) contrasts materialist with social constructionist approaches - including that of narrative. She argues that 'while an empowered life narrative is indeed a key tool for change in one context, the challenge of translating new narratives into action is often limited by objective constraints that cannot always be 'narrated' away in other contexts' (p. 57). Purcell (2011) details how community development trainees can learn from both the theoretical work of Freire and Gramsci but need to test these ideas through active community engagement. It is this connecting of narrative and other theoretical concepts with 
concrete situations that offers the potential for enhancing the potential of various forms of community health psychology.

\section{Acknowledgements}

We would like to thank the anonymous reviewers for their considered comments on an earlier version of this paper and Gerben Westerhof who not only acted as action editor but provided his own insightful comments.

\section{References}

Bamberg, M. (2011). Stories: big or small - why do we care? Narrative Inquiry, 7, 325-344.

Campbell, C. (2014). Community mobilisation in the $21^{\text {st }}$ century: updating our theory of social change. Journal of Health Psychology, 19, 46-59.

Campbell, C., \& Cornish, F. (eds.) (2014a). Community health psychology for the $21^{\text {st }}$ century: Pathways to health-enabling social change. Journal of Health Psychology, 19(1) [whole issue].

Campbell, C., \& Cornish, F. (2014b). Reimagining community health psychology: maps, journeys and new terrains. Journal of Health Psychology, 19, 3-15.

Dutt, A., \& Grabe, S. (2014). Lifetime activism, marginality, and psychology: Narratives of lifelong feminist activists committed to social change. Qualitative Psychology, 1, 107-122.

Erikson, E.H. (1963). Childhood and society ( $2^{\text {nd }}$ edition). New York: Norton.

Fagermoen, M.S. (1997). Professional identity: values embedded in meaningful nursing practice. Journal of Advanced Nursing, 25, 434-441.

Freeman, M. (2011). Stories, big and small: toward a synthesis. Theory \& Psychology, 21, 114-121.

Frost, D.M., \& Ouellette, S.C. (2011). A search for meaning: recognizing the potential of narrative research in social policy-making efforts. Sex Research and Social Policy, 8, 151-161.

Glen, A., Henderson, P., Humm, J., Meszaros, H., \& Gaffney, M. (2004). Survey of community development workers in the UK. London: Community Development Foundation.

Hancock, L., Mooney, G., \& Neal, S. (2012). Crisis social policy and the resilience of the concept of community. Critical Social Policy, 32, 343-364.

Hitlin, S. (2003). Values as the core of personal identity: drawing links between two theories of self. Social Psychology Quarterly, 66, 118-137.

Jarvis, D., Berkeley, N., \& Broughton, K. (2011). Evidencing the impact of community engagement in neighbourhood regeneration: the case of Canley, Coventry. Community Development Journal, 47, 232-247. 
Life Long Learning UK (2009). National Occupational Standards for Community Development.

Maton, K.I. (2008). Empowering community settings: agents of individual development, community betterment, and positive social change. American Journal of Community Psychology, 41, 421.

McAdams, D.P. (1993). The stories we live by. Personal myths and the making of the self. New York: Guilford.

McAdams, D.P. (2013). The redemptive self: Stories Americans live by. Second edition. New York: Oxford University Press.

McAdams, D.P., Diamond, A., de St. Aubin, E., \& Mansfield, E.D. (1997). Stories of commitment: The psychosocial construction of generative lives. Journal of Personality and Social Psychology, 72, 678-694.

Mishler, E.G. (1986). Research interviewing: context and narrative. Cambridge, MA: Harvard University Press.

Murray, M. (2012a). Critical health psychology and scholar-activist tradition. In C. Horrocks \& S. Johnson (eds.) Advances in health psychology: Critical approaches (pp. 29-43). London: Palgrave.

Murray, M. (2012b). Social and political health psychology in action. In D. Sheffield and M. Forshaw (eds.) Health psychology in action (pp. 128-137). London: Falmer.

Murray, M. (2014). Narrative psychology. In J. Smith (ed.) Qualitative psychology: (pp. ). London: Sage.

Murray, M., \& Campbell, C. (eds.) (2004). Community health psychology. Journal of Health Psychology, 9 (2), [whole issue\}.

Murray, M., \& Campbell, C. (eds.) (2004). Community health psychology: Promoting analysis and action for social change. Journal of Health Psychology, 9, 187-195.

Murray, M., \& Crummett, A. (2010). 'I don't think they knew we could do these sorts of things': social representations of community and participation in community arts by older people. Journal of Health Psychology, 15, 777-785.

Omoto, A.M., Snyder, M., \& Martino, S.C. (2000). Volunteerism and the life course: investigating age-related agendas for action. Basic and Applied Social Psychology, 22, 181-197.

Purcell, R. (2011). Community development and everyday life. Community Development Journal, 47 ,

Rayner M, Scarborough P, Allender S. (2006). Values underlying the National Service Framework for coronary heart disease in England: a discourse analysis. Journal of Health Services Research \& Policy, 11, 67-73. 
Sender, H., Carlisle, B., Hatamian, A., \& Bowles, M. (2010). Report on survey of community development practitioners and managers. London: Community Development Foundation.

Sools, A. (2013). Narrative health research: Exploring big and small stories as analytical tools. Healt (London), 17, 93-110.

Tilly, C. (2002). Stories, identities, and political change. Lanham, MD: Rowman \& Littlefield.

Wiggins, N., Kaan, S., Rios-Campos, T., Gaonker, R., Morgan, E.R., \& Robinson, J. (2013). Preparing community health workers to be agents of change. Journal of Community Practice, 21, 186202. 